\title{
Assessing the Response of Satellite Solar-Induced Chlorophyll Fluorescence and NDVI to Impacts of Heat Waves on Winter Wheat in the North China Plain
}

\author{
Chenjie Xian $\left(\mathbb{D},{ }^{1,2,3}\right.$ Li He $\mathbb{D}^{1,4}$ Zhengwei He, ${ }^{1,2}$ Dongjian Xue, ${ }^{2,5}$ and Zhe $\mathrm{Li}^{3}$ \\ ${ }^{1}$ State Key Laboratory of Geohazard Prevention and Geoenvironment Protection, Chengdu University of Technology, \\ Chengdu 610059, China \\ ${ }^{2}$ College of Earth Science, Chengdu University of Technology, Chengdu 610059, China \\ ${ }^{3}$ Chengdu Land Planning and Cadastral Affairs Center, Chengdu 610074, China \\ ${ }^{4}$ College of Tourism and Urban-Rural Planning, Chengdu University of Technology, Chengdu 610059, China \\ ${ }^{5}$ Key Laboratory of Geoscience Spatial Information Technology of Ministry of Land and Resources, \\ Chengdu University of Technology, Chengdu 610059, China
}

Correspondence should be addressed to Li He; heli2020@cdut.edu.cn

Received 22 April 2020; Revised 16 August 2020; Accepted 14 October 2020; Published 29 October 2020

Academic Editor: Budong Qian

Copyright (C) 2020 Chenjie Xian et al. This is an open access article distributed under the Creative Commons Attribution License, which permits unrestricted use, distribution, and reproduction in any medium, provided the original work is properly cited.

\begin{abstract}
Global warming has increased the chance of concurrent extreme climate events (weather or climate events that are rare within their statistical reference distributions in a particular place, such as heat waves, floods, and droughts). Crops grow best within specific temperature intervals, and excessive heat is detrimental to the physiological processes of crops and eventually affects yield levels. Analysing historical changes in concurrent extreme high temperatures is critical to preparing for and mitigating the negative effects of climatic change. The North China Plain (NCP) is the most important wheat production area in China. In this study, the spatiotemporal variations in temperature and heat wave trends in the NCP were analysed. Furthermore, we examined the potential of solar-induced chlorophyll fluorescence (SIF) to capture the influence of heat wave impacts on wheat crops in the NCP by comparing satellite remote sensing data of SIF and normalized difference vegetation index (NDVI) and validated groundbased yield data. The results indicate that temperatures and the number of heat wave days in the study region all show increasing trends, especially daily minimum temperature, which has increased by $0.38^{\circ} \mathrm{C}$ per decade for the past 30 years. Spatially, the southern NCP has suffered greater increasing-temperature trends and more heat wave days than the northern region. Regarding the response of SIF and NDVI to heat waves, SIF can better capture wheat yield decline due to heat waves compared to NDVI; thus, the SIF result indicated more sensitivity to heat waves compared to NDVI.
\end{abstract}

\section{Introduction}

With global warming of more than $\sim 1^{\circ} \mathrm{C}$, climate change has increased potential risks in different ecosystems and has a strong influence on terrestrial ecosystems $[1,2]$. Global warming and the risk of extremely high temperatures have also substantially increased the chance of concurrent extreme climate events such as droughts and heat waves [3]. Crops grow best within specific temperature intervals; excessive heat is detrimental to the physiological processes of crops and eventually affects yield levels $[4,5]$.

Existing projections reveal that it will require a doubling of current food production for the future population and economic growth [6]. Currently, the most important challenge for agriculture is the need to feed increasing numbers of people in the coming decades, while variations in climatic variables such as temperature and precipitation could significantly influence agricultural practices and crop yields 
$[7,8]$. Analysing historical changes of concurrent extreme high temperatures is critical to preparing for and mitigating the negative effects of climatic change [9]. Therefore, the response of crops to heat stress has received much attention in the past 20 years [10-13].

Wheat is one of the most-planted crops worldwide, and the harvested area of wheat in the North China Plain (NCP) ranks first among that of all crops [14]. China produced 17\% of the world's wheat and contained $11 \%$ of the world's wheat planting area in 2015, and the NCP is the most important wheat production region in China $[15,16]$. In wheat production, high temperatures can decrease the rate of grain filling, reduce the number of grains per ear, or reduce the subsequent rate of increase in harvest index, resulting in smaller grain yields [17-19].

With merits of long continuous time series and large area coverage, the satellite-derived Normalized Difference Vegetation Index (NDVI) is mostly utilized to reveal vegetation dynamics and the influence of extreme climatic events on plants [20-23]. However, previous studies have found that there are lag responses when the satellite-derived NDVI is employed to study the relationship between plants growing status and climatic variables such as temperature and precipitation $[24,25]$. The reason for the lag responses may be that the NDVI can only reflect variations in vegetation "greenness" and not a direct indicator of plant photosynthesis [26]. Recently, the successful retrieval of solar-induced chlorophyll fluorescence (SIF) from sensors has expanded vegetation monitoring with a new type of data $[27,28]$. When radiation is absorbed by plants, a small fraction of absorbed radiation is reemitted as SIF at longer wavelengths [29]. SIF is theoretically related to photosynthetic activity by way of mechanisms of energy dissipation [30]. Currently, global SIF products can be retrieved from platforms such as the Global Ozone Monitoring Experiment-2 (GOME-2) [28], Greenhouse gases Observing SATellite (GOSAT) [31], Orbiting Carbon Observatory (OCO2) [32], Chinese Carbon Dioxide Observation Satellite Mission (TanSat) [33], and TROPOspheric Monitoring Instrument (TROPOMI) [34], among which the GOME-2 SIF products enable the longest time series with global coverage.

Studies on SIF from the leaf to canopy scale indicate that SIF has a positive relationship with plant photosynthesis $[35,36]$. However, the response of satellite-derived SIF to heat waves affecting wheat crops on large scales is not yet well understood. Specifically, it is still unknown whether SIF can better capture the response of wheat to heat waves. In this study, the spatiotemporal variations in temperature and heat waves and their trends in the NCP were analysed. We further examined the potential of SIF to capture the influence of heat waves on wheat crops in the North China Plain by comparing satellite remote sensing data of SIF and NDVI and validated ground-based yield data.

\section{Materials and Methods}

2.1. Study Area. The North China Plain (NCP) mainly includes Hebei, Shandong, Henan, Shanxi, Jiangsu, and Anhui Provinces (Figure 1). 75\% of the total land area is cropland, and winter wheat and summer maize crops are planted in rotation in the study region [37]. The NCP has a temperate continental monsoon climate and rich solar-thermal resources. However, the precipitation in the NCP is relatively low, and only approximately $17-25 \%$ of precipitation falls in the winter wheat growing season [38]. The lack of rainfall affects the winter wheat yield, so irrigation is essential [39].

2.2. Climate Data, NDVI, SIF, and Yield Data. The climate data in this study include daily maximum air temperature $\left(T_{\max }\right)$, daily minimum air temperature $\left(T_{\min }\right)$, daily mean air temperature $\left(T_{\text {air }}\right)$, and precipitation (Pre). These data, which had a daily temporal resolution and a spatial resolution of $0.5^{\circ}$, were collected from the Climatic Research Unit (CRU) from 1982 to 2014. Annual $T_{\text {air }}, T_{\max }$, and $T_{\min }$ were calculated by averaging daily data over the whole wheat growing season, and the annual Predata were obtained by accumulating daily Predata.

The latest Global Inventory Modelling and Mapping Studies (GIMMS) NDVI values from the Advanced Very High Resolution Radiometer (AVHRR) instrument were employed in this study. To minimize the effects of clouds, aerosol contamination, and solar zenith angles, the highest NDVI values were employed to determine the 15-day NDVIs. To maintain consistency with the temperature and precipitation data, the spatial resolution of the NDVI data was resampled from $8 \mathrm{~km}$ to $0.5^{\circ}$.

Satellite SIF data with a $0.5^{\circ}$ spatial resolution from 2007 to 2014 were applied. These data were obtained from the GOME-2 instrument onboard EUMETSAT's polar orbiting Meteorological Operational Satellites (MetOp-A and MetOp-B). MetOp-A was launched in October 2006, and the spectral range between 240 and $790 \mathrm{~nm}$ is covered by four detector channels. The spectral region from 720 to $758 \mathrm{~nm}$ of the fourth channel (590-790 $\mathrm{nm}$ with spectral resolution of $0.5 \mathrm{~nm}$ and a signal-to-noise ratio up to 2000) onboard MetOp-A was used to evaluate the SIF at $740 \mathrm{~nm}$ [28]. To exclude the effects of heavy clouds, pixels with cloud cover greater than $30 \%$ were removed from the SIF product, and then the data was merged to monthly average values.

We downloaded data on ground statistical wheat crop yield at the province level (including Hebei Province, Henan Province, Shanxi Province, Shandong Province, Anhui Province, and Jiangsu Province) from 2007 to 2014 from the Natural Bureau of Statistics of China (http://data.stats.gov. $\mathrm{cn} /)$.

2.3. Calculation of Wheat Growing Season Average Values and Change Percent. To calculate the wheat growing season average values of the parameters used in this study, the phenology results of Xiao et al., 2013, [40] were employed here. Xiao et al. obtained wheat phenological data from 36 agroexperimental stations in the North China Plain. According to the investigated stations, the date of sowing was delayed on average by 0.15 days, and the anthesis date occurred an average of 0.25 days early from 1981 to 2009 in the NCP. The average start day of the year (DOY) of the wheat season was 281 , and the end DOY of the wheat season 


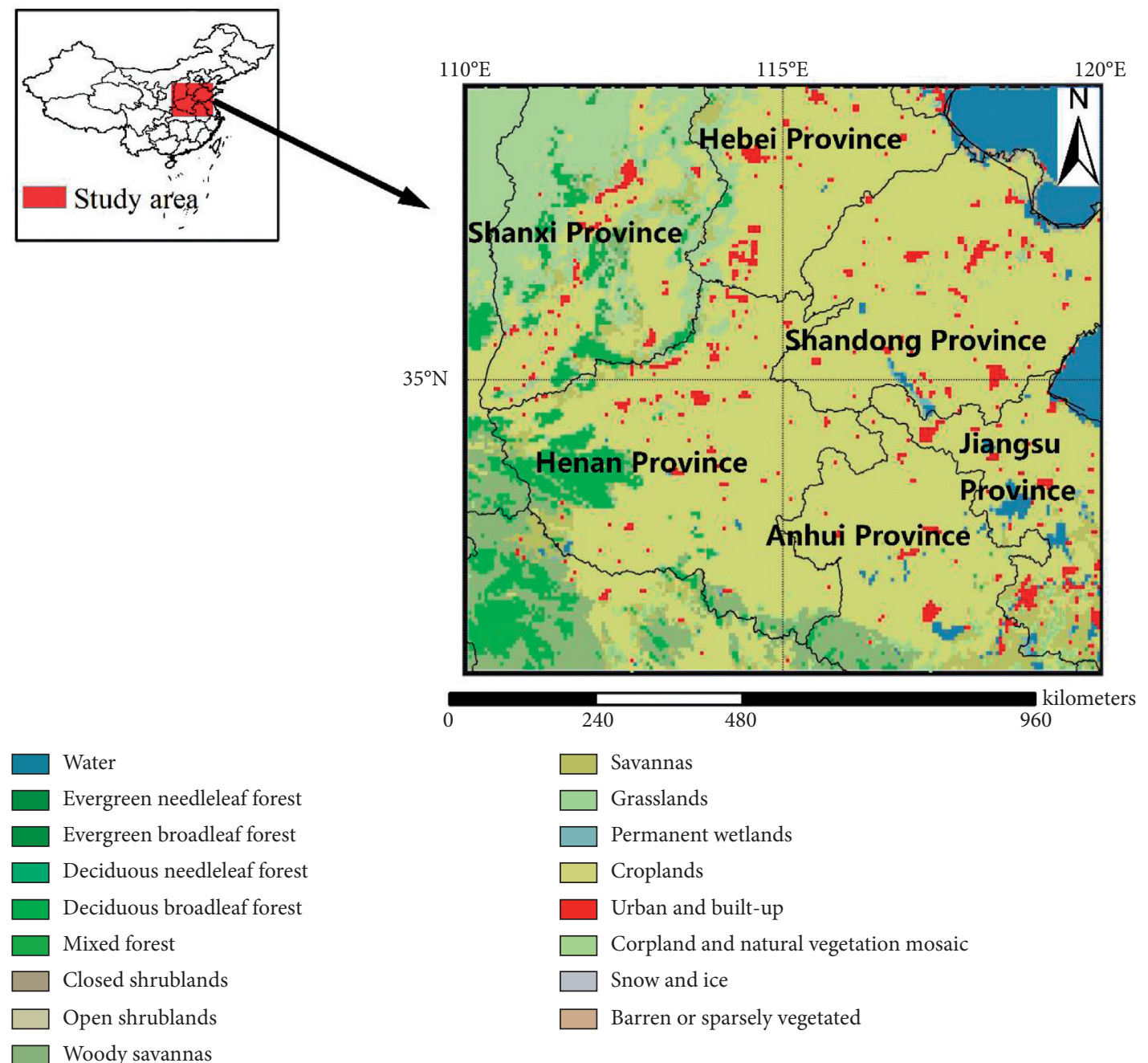

FIgURE 1: The location and land cover of the study area. The 2014 MODIS land cover map with IGBP land cover classification at 0.05 -degree spatial resolution is employed.

was 157 in the following year [40]. In this paper, we used monthly average temperature, NDVI, and SIF data; thus, changes in winter wheat phenology of less than 0.3 days had little influence on the final results with a monthly temporal resolution. Thus, we calculated the average values of temperature, NDVI, and SIF during the wheat growing season, from October of a given year to May of the following year. As shown by previous studies, high temperatures during other periods, such as the postanthesis period, also have a significant negative impact on wheat growth $[41,42]$. Thus, the average temperature of the whole growing period was employed in this study. We calculated the spatial mean of all variables at the whole study region and the province levels. The spatial mean value at the province level was calculated by using the Chinese vector map to obtain the extent of the provinces of the NCP. The anomalies were computed as departures from the multiyear means from 1983 to 2014 for all datasets. The relative changes in NDVI were calculated as the anomalies divided by their multiyear mean value, and the equation is shown as follows:

$$
\frac{\Delta \mathrm{SIF}}{\operatorname{NDVI}(t)}=\frac{\operatorname{SIF} / \mathrm{NDVI}_{\text {anomaly }}(t)}{\overline{\mathrm{SIF}} / \mathrm{NDVI}},
$$

where $\Delta$ SIF/NDVI $(t)$ denotes the relative change in the SIF or NDVI compared with the multiyear mean SIF or NDVI value $\overline{\operatorname{SIF} / N D V I}$ at time $t$ and $\operatorname{SIF} / \mathrm{NDVI}_{\text {anomaly }}(t)$ is the anomaly of SIF or NDVI at time $t$.

2.4. Calculation of Heat Wave Index and Wheat Pixel Extraction. The standardized heat index (SHI) was proposed by Raei et al. [43], who used the probability density function (PDF) of long-term daily temperature records to calculate heat waves. First, a temperature PDF was constructed for a window of 15 days centred around the day of interest, and the empirical probability for each temperature level was calculated using the Gringorten plotting position (equation (2)). Then, the SHI was estimated using the empirical probability of the three-day-averaged mean daily temperature (equation (3)). Finally, if the value of $\mathrm{SHI} \geq 1$, it 
was defined as a heat wave event, which was associated with three-day-averaged daily temperatures exceeding the $\sim 84^{\text {th }}$ percentile of the long-term temperature PDF. In this paper, we employed the SHI to analyse heat wave events in the NCP, and the input data were the daily mean temperatures.

$$
p\left(T_{i}\right)=\frac{r_{i}-0.44}{n+0.12},
$$

where $T_{i}$ is the $i^{\text {th }}$ observed mean daily temperature in the constructed PDF and $r_{i}$ is the rank of $T_{i}$ from the smallest value. The SHI for the temperature level was then estimated as follows:

$$
S H I(\widehat{T})=\Phi^{-1}(p(\widehat{T})),
$$

where $\Phi$ is the standard normal distribution.

The Spatial Production Allocation Model (SPAM) and the Moderate Resolution Imaging Spectroradiometer (MODIS) land cover product (MCD12C1) with the International Geosphere-Biosphere Programme (IGBP) land cover classification were used to extract wheat pixels in the NCP. The SPAM contains the harvested area and yield products for 40 crops (including cereal crops, oil crops, and other crops) globally and has been widely used to study the spatiotemporal distribution of crops [44]. Using a classic cross-entropy approach, the SPAM makes plausible allocations of crop production in geopolitical units (country or state) into individual pixels through judicious interpretation of all accessible evidence such as production statistics, farming systems, satellite images, crop biophysical suitability, crop prices, local market access, and prior knowledge. The 5-by-5-minute resolution maps obtained with the SPAM for major crops agreed well with validated groundbased results [44-46]. The MODIS land cover data includes 17 land cover types: 11 natural vegetation classes, 3 developed and mosaicked land types, and 3 nonvegetated land types [47].

2.5. Calculation of Linear Trends. In this paper, the temporal and spatial variations in temperature, precipitation, and SHI from 1983 to 2014 were analysed by the nonparametric Theil-Sen slope estimator. The Theil-Sen estimator determines the slope by selecting the median slope of all lines through pairs of two-dimensional sample points. Unlike ordinary linear regression, the Theil-Sen approach can offer analytical estimates of confidence intervals, robustness to outliers, and testable assumptions regarding residuals and requires limited a priori information regarding measurement errors [48]. To determine the sensitivity of SIF and NDVI to heat waves, the annual NDVI and SIF change percentages were averaged by bins of the SHI anomalies with an interval of 5 days, and then the Theil-Sen slope was calculated. Due to the different periods of SIF and other data, the period of SIF was from 2007 to 2014, and we also calculated the sensitivity and Theil-Sen slopes between SIF/NDVI and heat wave days using datasets from 2007 to 2014.

\section{Results}

3.1. Temporal Change Trends of Heat Waves. Figures 2(a), 2(b), and 2(c) show the annual variations in the wheat growing season average $T_{\text {air }}, T_{\max }$, and $T_{\min }$ from 1983 to 2014. Although there were fluctuations among the annual temperature values, the overall changes in $T_{\text {air }}, T_{\max }$, and $T_{\min }$ were positive. $T_{\text {air }}$ and $T_{\min }$ showed significant increases, with values of $0.28^{\circ} \mathrm{C} / 10 \mathrm{a}$ and $0.38^{\circ} \mathrm{C} / 10 \mathrm{a}$, respectively (10a means per 10 years; $R^{2}=0.23$ and $p<0.01$ for $T_{\text {air }}$; $R^{2}=0.35$ and $p<0.01$ for $T_{\min }$ ). The temperatures in 2002 and 2007 were the highest of the period from 1983 to 2014 . In 2002 and 2007 , the values of $T_{\text {air }}$ were $0.9^{\circ} \mathrm{C}$ and $1.31^{\circ} \mathrm{C}$ higher than the multiyear average temperatures, the values of $T_{\max }$ were $0.9^{\circ} \mathrm{C}$ and $1.4^{\circ} \mathrm{C}$ higher, and the values of $T_{\min }$ were $1^{\circ} \mathrm{C}$ and $1.5^{\circ} \mathrm{C}$ higher, respectively.

With the same trends as the temperature values, the number of heat wave days (SHI) in the study region also increased significantly from 1983 to 2014 (Figure 2(d)). During these 32 years, the number of heat wave days increased by 10 days per decade. With the most heat wave days, $26 \%$ and $25 \%$ of the whole wheat growing season in 2002 and 2007 suffered from heat waves, respectively, which corresponded with the increase in temperatures. However, the annual precipitation variations in the study region were not exactly the same as the variations in temperature and number of heat wave days (Figure S1 in Supplementary Materials). In 2002 and 2007, during which serious heat waves occurred, the precipitation was higher than the average values.

3.2. Spatial Change Trends of Heat Waves. Figure 3 indicates the spatial distributions of temperature and heat wave days in the study region. From 1983 to 2014, 95.2\% of the $T_{\text {air }}$ values in the NCP wheat planting areas showed increasing trends at a rate of $0.32^{\circ} \mathrm{C} / 10 \mathrm{a}$, and $77 \%$ of the regions were statistically significant at the level of 0.05 (Figures 3(a) and 3(b)). For $T_{\max }$ (Figures 3(c) and 3(d)), approximately $81 \%$ of the regions experienced increasing trends, the average increasing rate was $0.21^{\circ} \mathrm{C} / 10 \mathrm{a}$, and the percentage of areas with statistical significance at the 0.05 level was $54 \%$ lower than that of $T_{\text {air }}$. Prominent increasing trends were observed for $T_{\min }, 100 \%$ of the total wheat planting areas showed increasing trends, $84 \%$ of the regions had statistical significant at the 0.05 level, and the average increasing rate was the highest among all temperature variables with a rate of $0.41^{\circ} \mathrm{C} / 10 \mathrm{a}$ (Figures 3(e) and 3(f)). As shown in Figures 3(g) and $3(\mathrm{~h})$, the study regions suffered an increasing number of heat wave days per wheat growing season in almost all areas during 1983-2014, with more than $88.4 \%$ of the areas showing statistical significance at the 0.05 level.

Although average values of temperature and heat wave days indicated increasing trends throughout the whole study area, the trends of these variables were spatially heterogeneous. In the southern study region (mainly including Henan, southern Shandong, Anhui, and Jiangsu Provinces), $T_{\mathrm{air}}, T_{\max }$, and $T_{\min }$ all experienced prominent increasing trends with rates of $0.38^{\circ} \mathrm{C} / 10 \mathrm{a}, 0.34^{\circ} \mathrm{C} / 10 \mathrm{a}$, and 


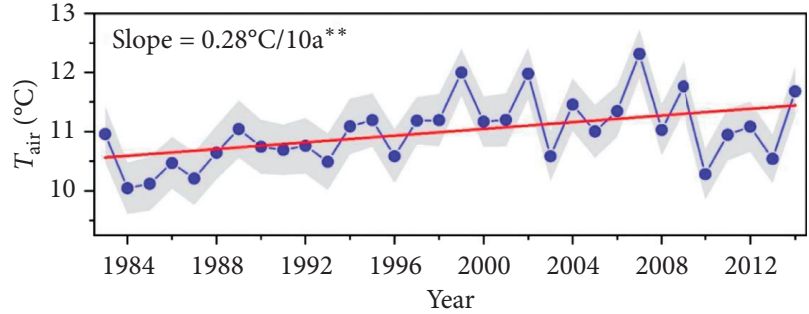

(a)

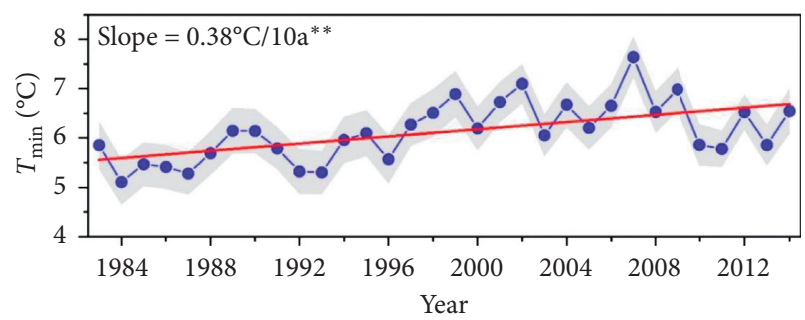

(c)

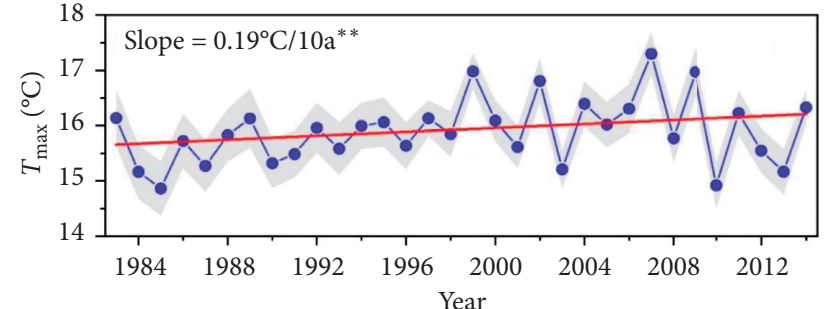

(b)

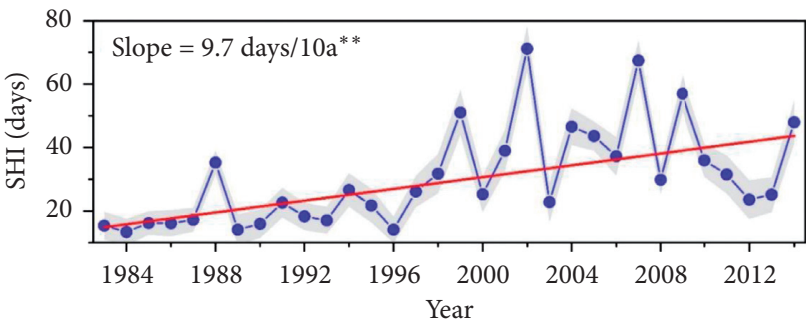

(d)

FIgure 2: The linear trends of annual average. (a) $T_{\text {air }}$ (b) $T_{\max }$ (c) $T_{\min }$. (d) SHI.

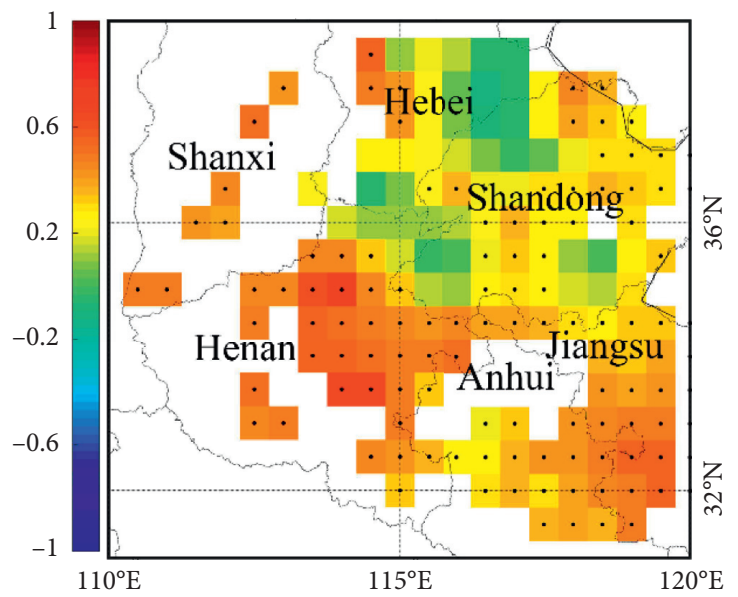

(a)

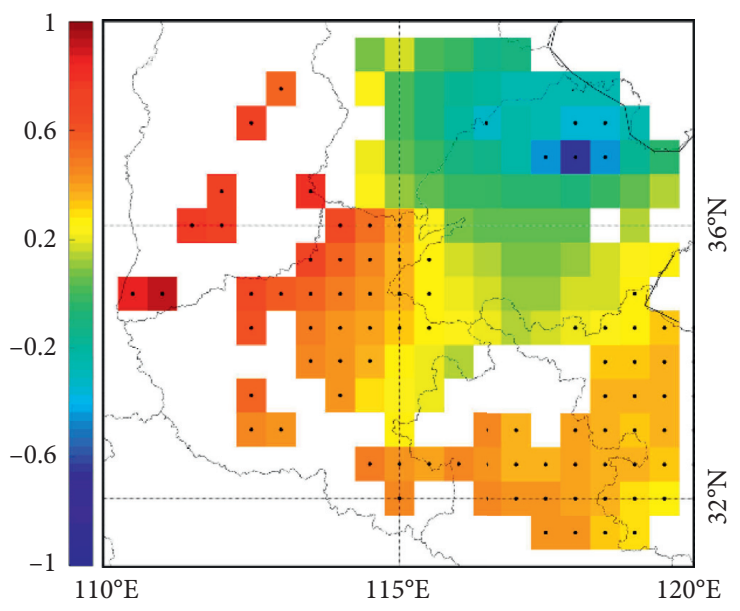

(c)

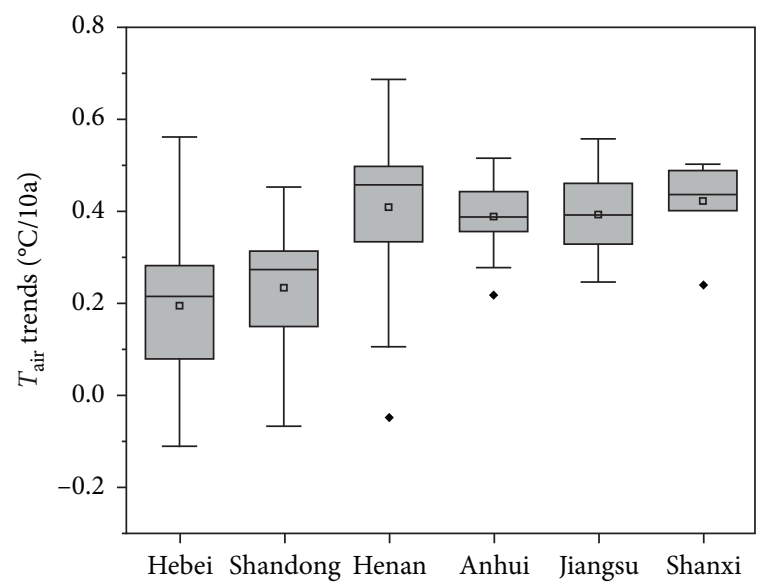

(b)

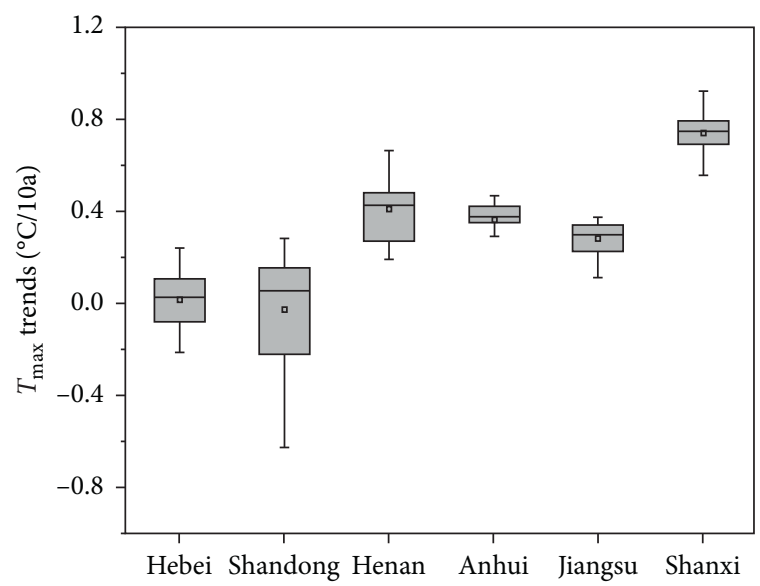

(d)

Figure 3: Continued. 


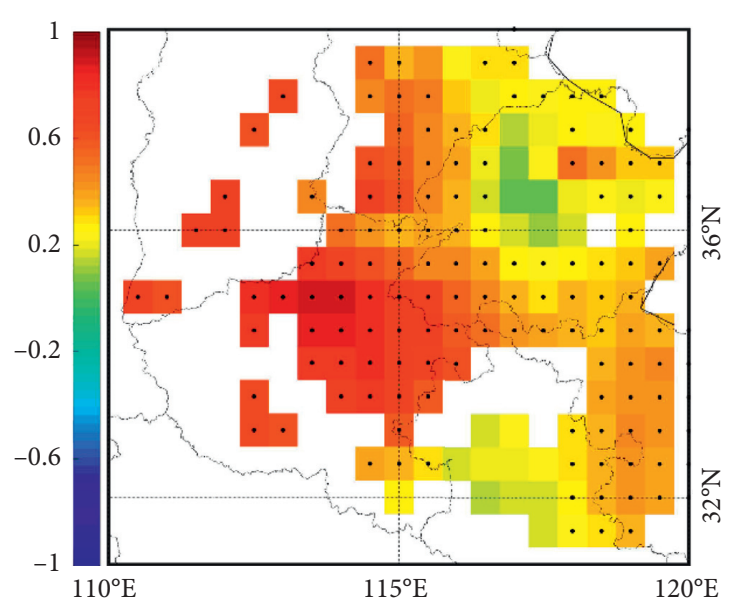

(e)

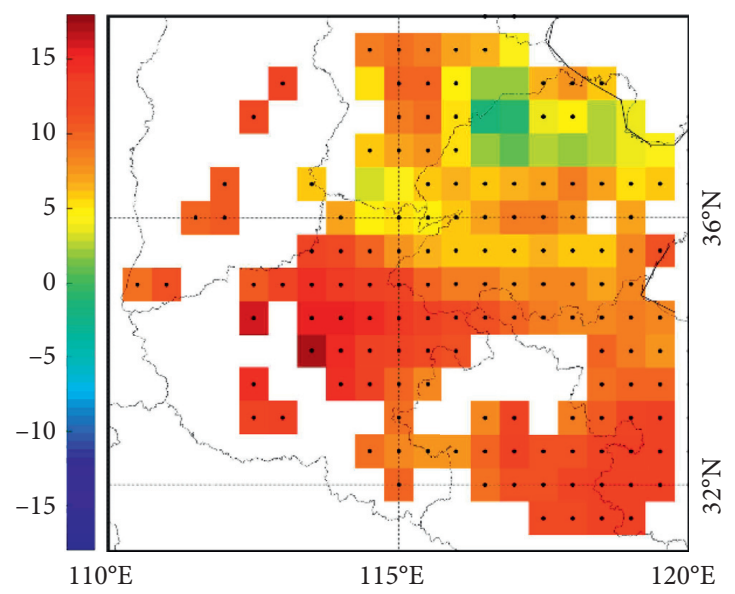

(g)

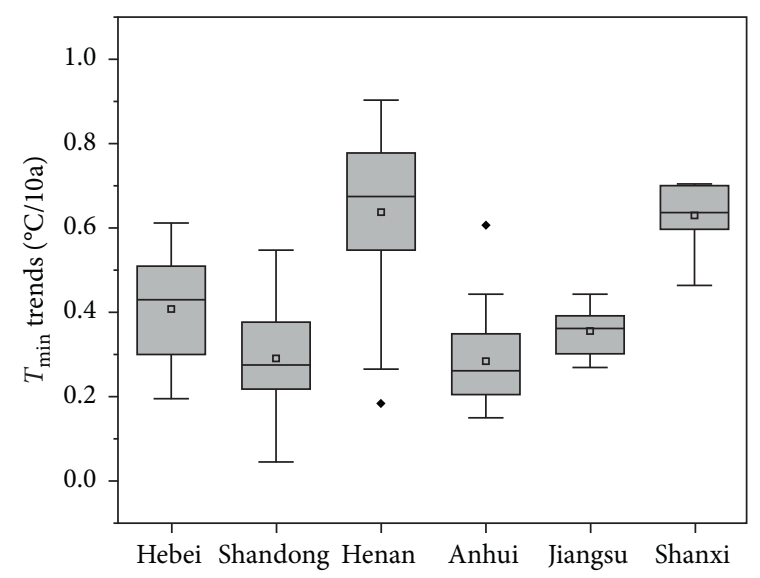

(f)

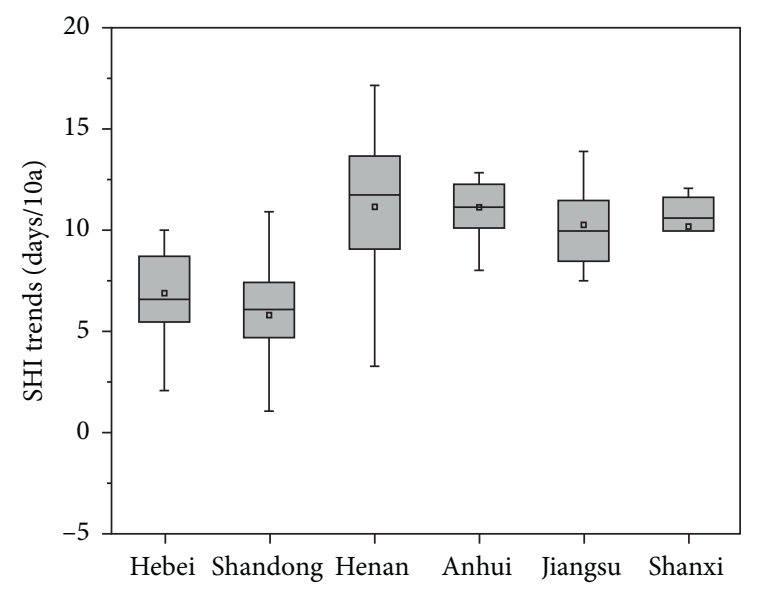

(h)

Figure 3: Spatial maps of the trends in the annual mean. (a) $T_{\text {air }}\left({ }^{\circ} \mathrm{C} / 10 \mathrm{a}\right),(\mathrm{b}) T_{\text {air }}$ trends $\left({ }^{\circ} \mathrm{C} / 10 \mathrm{a}\right),(\mathrm{c}) T_{\max }\left({ }^{\circ} \mathrm{C} / 10 \mathrm{a}\right),(\mathrm{d}) T_{\max }$ trends $\left({ }^{\circ} \mathrm{C} / 10 \mathrm{a}\right)$, (e) $T_{\min }\left({ }^{\circ} \mathrm{C} / 10 \mathrm{a}\right)$, (f) $T_{\min }$ trends $\left({ }^{\circ} \mathrm{C} / 10 \mathrm{a}\right)$, and (g) SHI (days/10a) and the boxplot of spatial average values of (h) SHI trends (days/10a) for each province. The location of each province is shown in (a), and panels (c), (e), and (g) are the same as panel (a). The black dots in the figures indicate trends that are statistically significant $(P<0.05)$.

$0.44^{\circ} \mathrm{C} / 10 \mathrm{a}$, respectively. The northern part of the study region, including Hebei and the northern part of Shandong Province, was observed to have much smaller increasing rates for $T_{\text {air }}, T_{\max }$, and $T_{\min }$. The mean values of the $T_{\text {air }}$ trends, $T_{\max }$ trends, and $T_{\min }$ trends in the northern part of the study region were $0.2^{\circ} \mathrm{C} / 10 \mathrm{a},-0.001^{\circ} \mathrm{C} / 10 \mathrm{a}$, and $0.34^{\circ} \mathrm{C} / 10 \mathrm{a}$, respectively. Similar to the distributions of temperature trends, almost all wheat planting regions suffered an increasing number of heat wave days during 1983-2014. In the southern part of the study region, the increasing trend in the number of heat wave days was 10.7 days per decade. However, in the northern part of the study region, the SHI tended to show a relatively slight increasing trend at a rate of 7.5 days/10a in wetter regions (with positive Pre trends, Figure S2 in Supplementary Materials).

As indicated by the variations in the average values of temperature and SHI trends over varying latitudes (Figure 4), the temperature trends show a near-normal distribution along latitude. All the temperature variables and SHI reached their maximum values at a latitude of $33^{\circ} \mathrm{N}$ (the central parts of Jiangsu and Anhui Provinces and the southern part of Henan Province). The northern and southern parts of the study region all showed smaller increasing trends for $T_{\text {air }}, T_{\max }$, and $T_{\min }$. However, when the SHI trends reached their maximum values at the latitude of $33^{\circ} \mathrm{N}$, the number of heat wave days started to increase after slightly decreasing. Furthermore, the decreasing rate for the Pre of the southern part of the study region was $-0.15 \mathrm{~mm} /$ $10 \mathrm{a}$, which was approximately 2 times greater than that of the whole study region (Figure S2 in Supplementary Materials).

3.3. Change Trends of SIF and NDVI. Figure 5 shows the annual variations in the wheat growing season average NDVI and SIF from 1983 to 2014 (SIF from 2008 to 2014) in 6 provinces. The overall changes in the NDVI were significantly positive. In Henan and Anhui Provinces, the NDVI showed the largest increasing trend, with values of 0.0266 / 


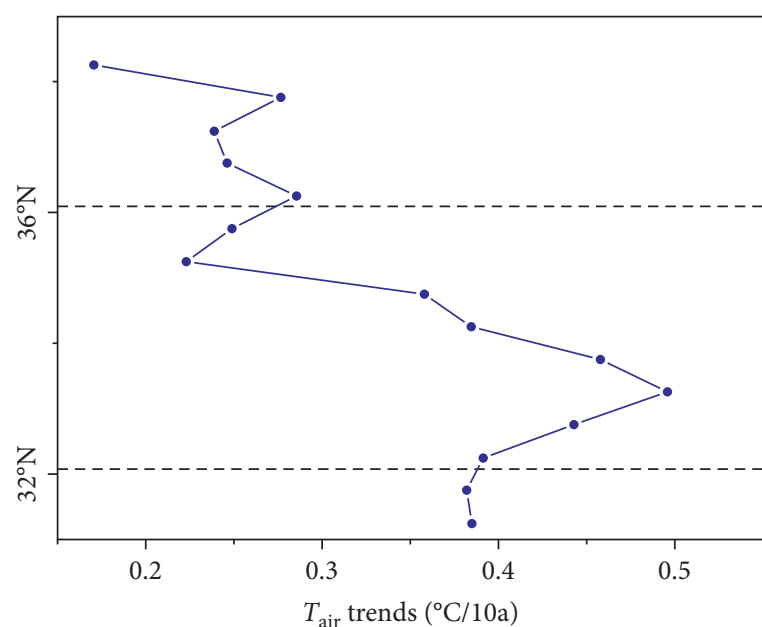

(a)

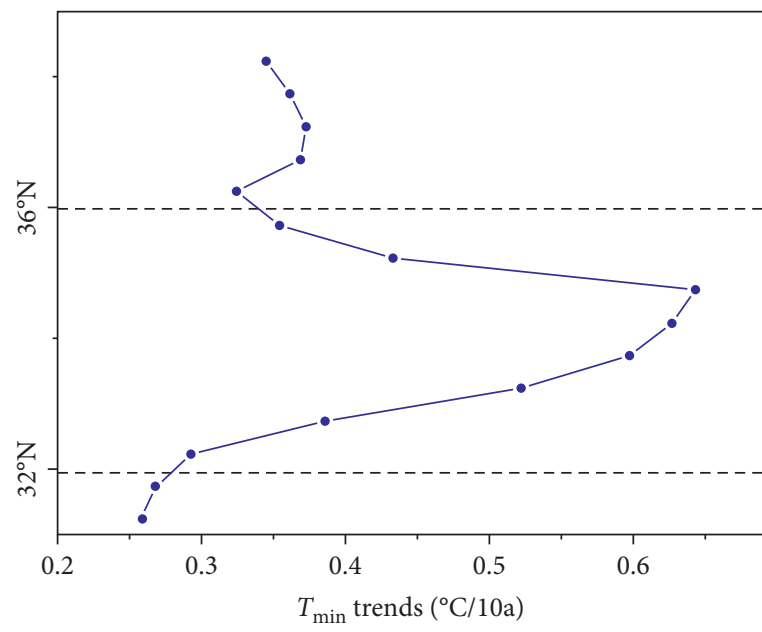

(c)

Figure 4: The trends of the spatial averages of (a) $T_{\text {air }}$,

10a and 0.0273/10a, respectively (Figures 5(c) and 5(d)). Wheat coverage in Shanxi Province showed the smallest increasing trend, and the NDVI increased by $0.00684 / 10 \mathrm{a}$ from 1983 to 2014 (Figure 5(f)), which was 63\% smaller than the average increasing trend of 6 provinces $(0.01874 / 10 \mathrm{a})$ and $75 \%$ smaller than the trend in Anhui Province. Meanwhile, the increasing trend in the number of heat wave days per wheat growing season in Shanxi Province tended to be as large as that in Anhui Province (Figure 3(g)). During 2008-2014, SIF also showed increasing trends. Wheat coverage in Henan Province showed the largest increasing trend $(0.26939 / 10 \mathrm{a}$, Figure 5(c)). In Jiangsu Province, SIF presented a larger increasing trend than that in Anhui Province; however, in Anhui Province, the increasing trend of NDVI was greater than the trend in Jiangsu Province (Figures 5(d) and 5(e)).

3.4. Different Responses of SIF and NDVI to Heat Waves. A greater number of heat wave days would significantly decrease the SIF and NDVI (Figure 6). Although the SIF and NDVI all decreased with the increase in the number of heat

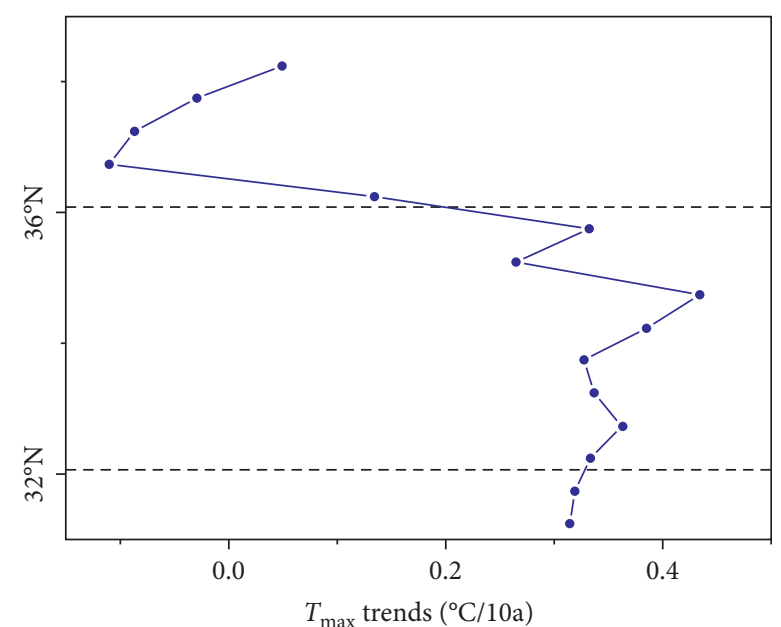

(b)

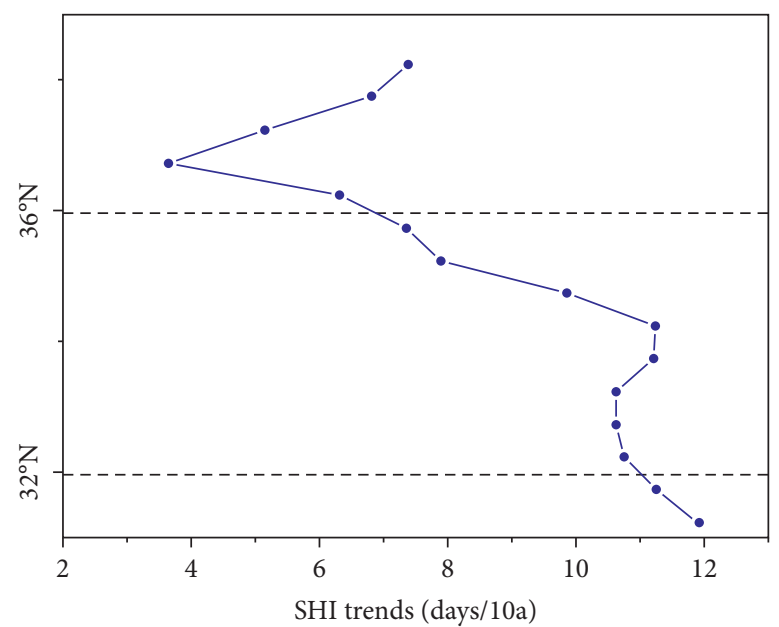

(d)

(b) $T_{\max }$, (c) $T_{\min }$, and (d) SHI over latitude with $0.5^{\circ}$ bins.

wave days per wheat growing season, the response amplitude varied among SIF and NDVI. As indicated by the linear fit between SIF/NDVI change percent and SHI anomaly, when the number of heat wave days increased 1 day per wheat growing season annually, the SIF values of the NCP decreased by $4.4 \%$ (as indicated by the slope in Figure 6(b)), which was almost 3 times larger than the decrease in NDVI $(-1.6 \%$ for the NDVI, as indicated by the slope in Figure 6(a)).

To further compare the sensitivity of SIF and NDVI to heat waves, the threshold values of heat wave days when the SIF/NDVI changed from positive to negative were calculated using the linear fit above. The threshold value calculated for NDVI was 1.7 days ( \pm 1.2 days), meaning that when the wheat suffered a heat wave for nearly 2 days, the NDVI just began to show a response to the heat waves. The value for the SIF was less than 1 day $(0.8 \pm 0.6$ days $)$, which indicated a nearly immediate response when wheat suffered heat waves (Figure 7).

To determine the reason for the different responses of SIF/NDVI to heat waves, we compared the wheat growing 


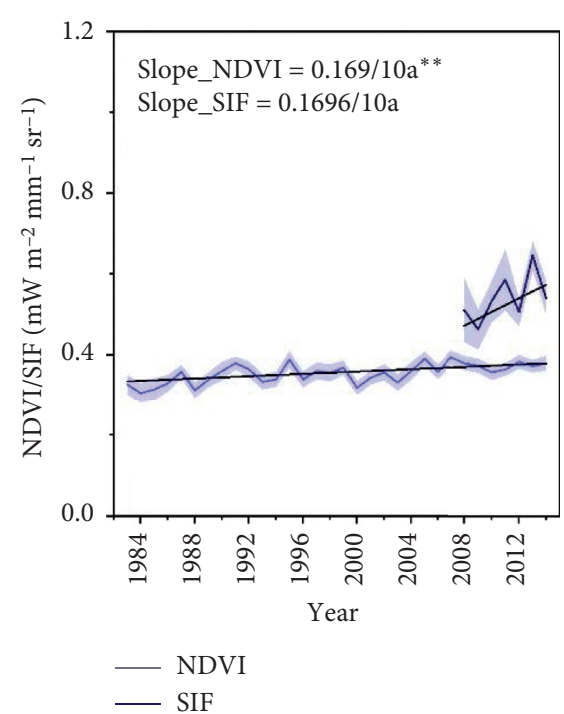

(a)

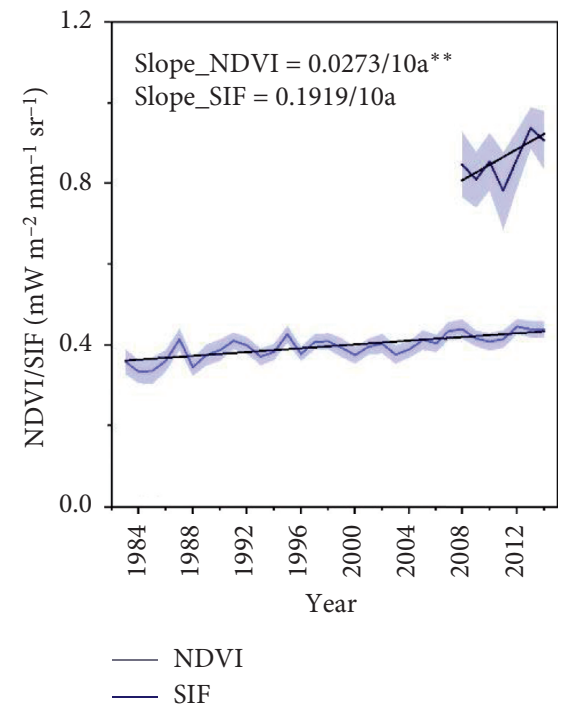

(d)

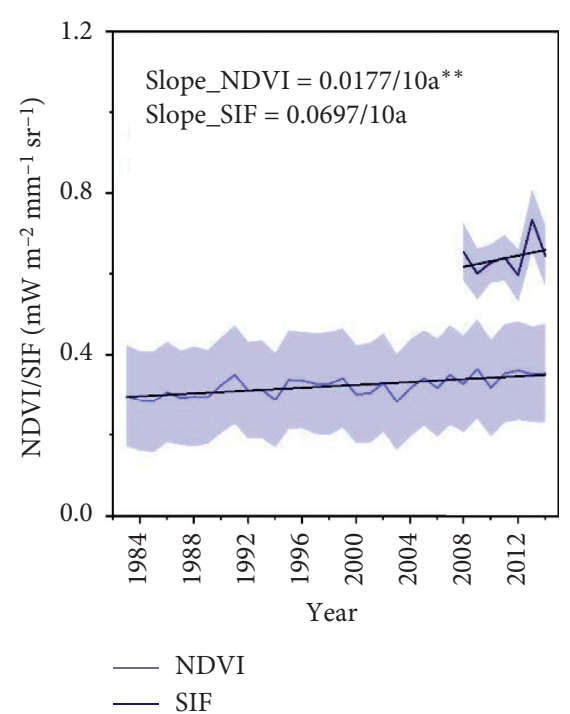

(b)

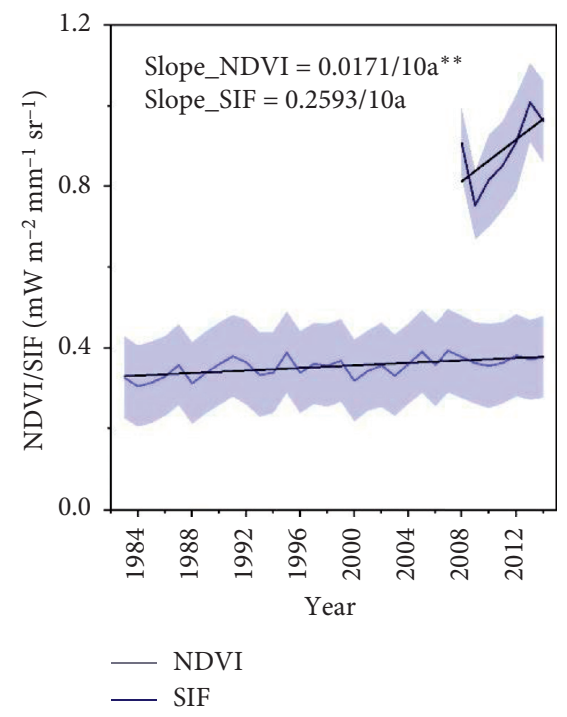

(e)

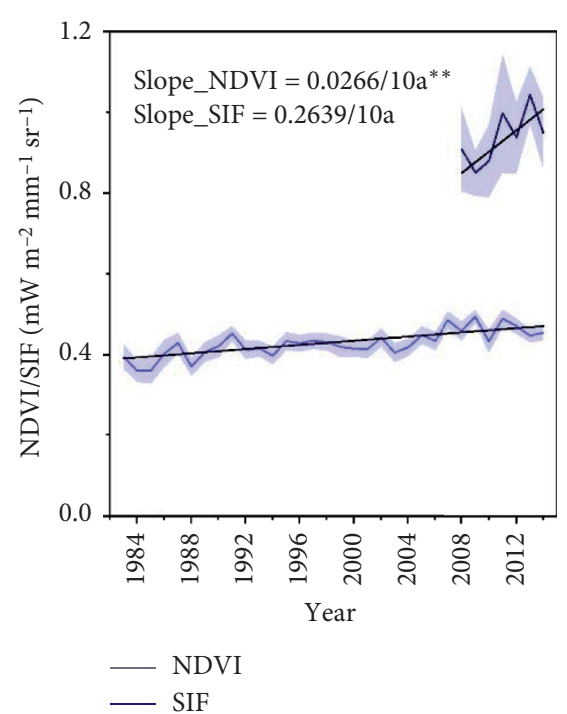

(c)

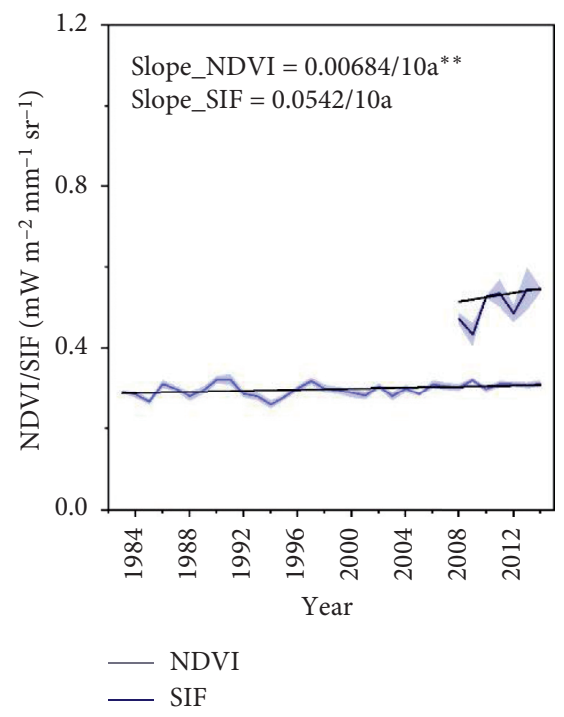

(f)

FIGURE 5: Linear trends of annual average NDVI (period: 1983-2014) and SIF (period: 2008-2014) in (a) Hebei, (b) Shandong, (c) Henan, (d) Anhui, (e) Jiangsu, and (f) Shanxi Provinces $\left(^{* *}\right.$ indicates $P<0.01$; ${ }^{*}$ indicates $\left.P<0.05\right)$.

season mean SIF/NDVI over the study area with the wheat yield at the province scale (Figure 8). The results revealed that SIF had a stronger relationship with yield compared to NDVI, which indicates that SIF can better explain the variations in yield. The determination coefficient for the linear fit between SIF and yield was 0.5 (Figure 8(a)), while the determination coefficient for NDVI was 0.42 (Figure 8(b)). In 2009, the NCP suffered serious heat waves, which resulted in a wheat yield decrease of $\sim 5.7 \%$ (Figure 8(c)). The SIF in 2009 showed a significant decline of $15 \%$ compared with the multiyear SIF values during 2008-2014, while the NDVI in 2009 showed nearly no decrease $(-0.87 \%)$. Thus, SIF can better capture wheat yield decline due to heat waves compared to NDVI and NDVI overestimates the wheat yield when wheat suffers heat waves.
Figure 9 indicates the spatial distributions of the 2009 percent change in wheat yield, SIF, and NDVI. In 2009, the whole NCP region suffered yield decline due to heat waves (Figure 9(a)). Furthermore, the SIF in 2009 decreased compared with the values during 2008-2014, which can better capture the wheat yield decline (Figure 9(b)). Meanwhile the NDVI indicated no response to the yield decline due to heat waves in 2009, except in Anhui Province (Figure 9(c)).

\section{Discussion}

4.1. Spatiotemporal Variations in Heat Waves. For the past 30 years, the temperature of the whole NCP has increased by $0.28^{\circ} \mathrm{C}$ per decade, which is $0.12^{\circ} \mathrm{C}$ higher than the global average warming trend [49], and the minimum temperature 


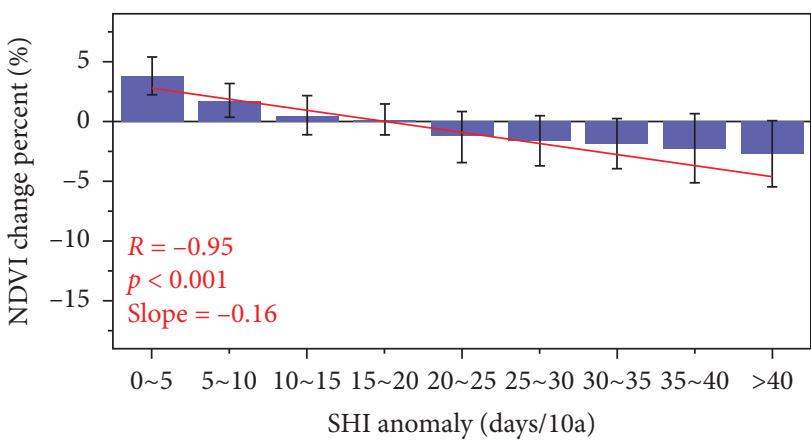

(a)

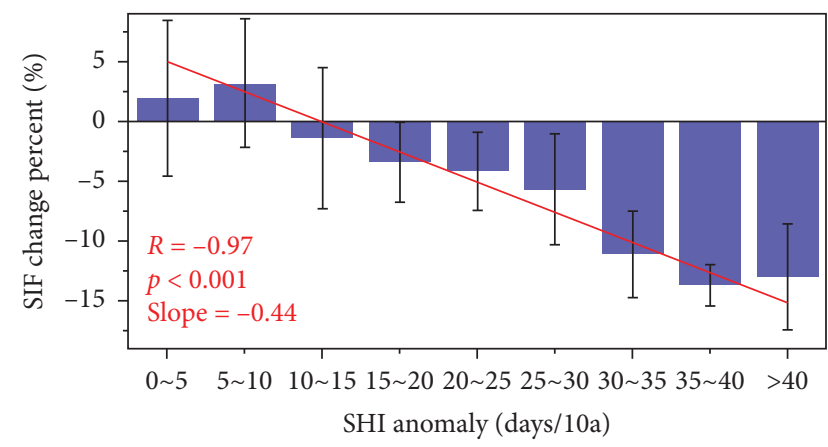

(b)

FIGURE 6: The comparison between (a) NDVI change percent and (b) SIF change percent and the number of heat wave days anomaly per decade (SHI anomaly) as compared with multiyear values during 2008-2014. The NDVI and SIF change percentages were calculated by averaging SHI anomaly bins with intervals of 5 days.

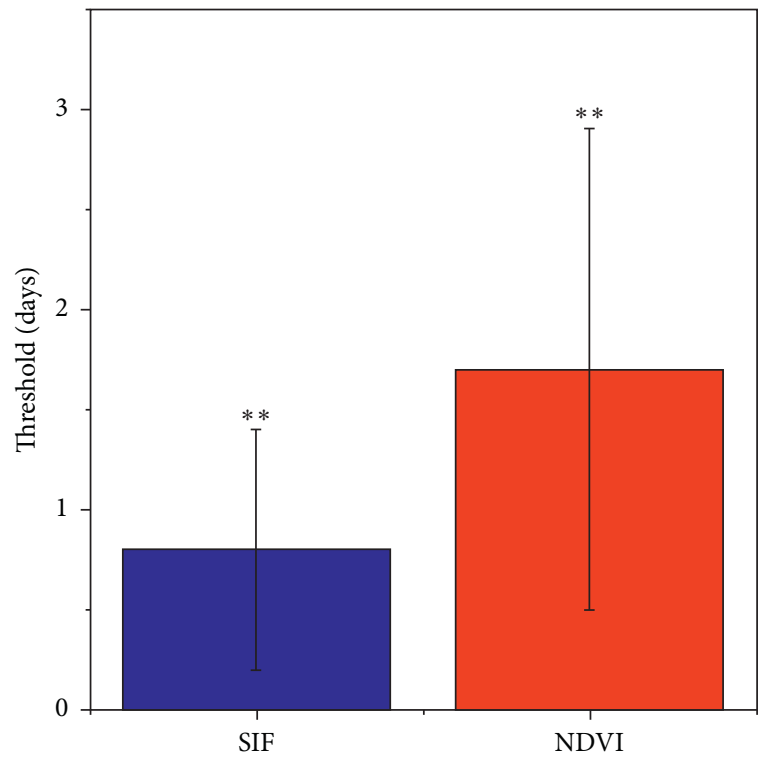

FIGURE 7: The threshold of the number of days that indicated NDVI/SIF change percent changed from a positive value to a negative value, derived from NDVI and SIF during 2008-2014. The threshold days were calculated from the linear fit between the averaged NDVI/SIF change percent and the bins of SHI heat wave anomalies (as depicted in Figure 6). ${ }^{* *}$ indicates that $P<0.01$ (note that the unit of the threshold in this figure is days per year, which differs from the unit in the above figures (days per 10 years)).

specifically has increased by $0.38^{\circ} \mathrm{C}$ per decade. $T_{\min }$ in the NCP usually indicates the night-time temperature [50]. The increase in temperature may be due to the disappearance of the $0^{\circ} \mathrm{C}$ isotherm and the rise in spring temperatures [51]. Many studies have demonstrated that an increase in minimum temperature will negatively affect crop growth and final yield $[52,53]$. Thus, the increase in daily minimum temperatures may pose a risk to wheat crop growth and the final yield in the North China Plain. Furthermore, Nicholls indicated that high night-time temperatures can further exacerbate heat wave conditions, which is consistent with the results in this study [54]. In 2002 and 2007, the NCP suffered the most serious heat waves, and $T_{\min }$ of the study region was also the highest for the past 30 years. With increasing temperature, the number of heat wave days in the NCP indicates increasing trends.

In this work, the spatial distributions of temperature and precipitation trends show that spatial heterogeneity is obvious. There is an obvious increase in temperature $\left(>0.4^{\circ} \mathrm{C} /\right.$ $10 \mathrm{a}$ for $T_{\text {air }},>0.3^{\circ} \mathrm{C} / 10 \mathrm{a}$ for $T_{\max }$, and $>0.5^{\circ} \mathrm{C} / 10 \mathrm{a}$ for $\left.T_{\min }\right)$ and an obvious decrease in precipitation $(<0 \mathrm{~mm} / 10 \mathrm{a}$, Figure S2 in Supplementary Materials) in the southern North China Plain. However, in the north of the study region, the temperature increase trends tend to be slight $\left(<0.3^{\circ} \mathrm{C} / 10\right.$ a for $T_{\text {air }},<0.1^{\circ} \mathrm{C} / 10$ a for $T_{\max }$, and $<0.4^{\circ} \mathrm{C} / 10$ a for $\left.T_{\text {min }}\right)$, and precipitation shows increasing trends $(>0 \mathrm{~mm} /$ 10a). Due to the spatial heterogeneity of water resources and the opportunity cost of agricultural labour forces between the north and south of the North China Plain, there was an increase in areas planted with winter wheat in the south [55]. As a result, in the south of the study region, there may be a more serious risk to extreme climate events than in the north. Previous studies indicated that there was an increase in extremely hot days and drought events, especially in the southern North China Plain, which is consistent with the results in this work $[55,56]$.

\subsection{Advantages of SIF to Reveal the Influence of Heat Waves in} Wheat. SIF and NDVI show different responses to heat waves in the NCP. When the heat wave days of the study region increase by 10 days per decade, the SIF indicates a larger decrease than that of the NDVI. Heat waves could significantly decrease the wheat photosynthesis rate and decrease the final yield [57-59]. Early detection of heat wave impacts on wheat can help policymakers formulate adaptations to buffer the influence of heat waves on wheat yield [60]. The sensitivity analysis in this study demonstrates that SIF can detect heat stress in wheat within 1 day and shows higher sensitivity to heat waves than NDVI. The results are consistent with Song et al.'s study, which demonstrated that SIF can detect heat stress in wheat crops approximately 16 days earlier than traditional vegetation indices [61]. 


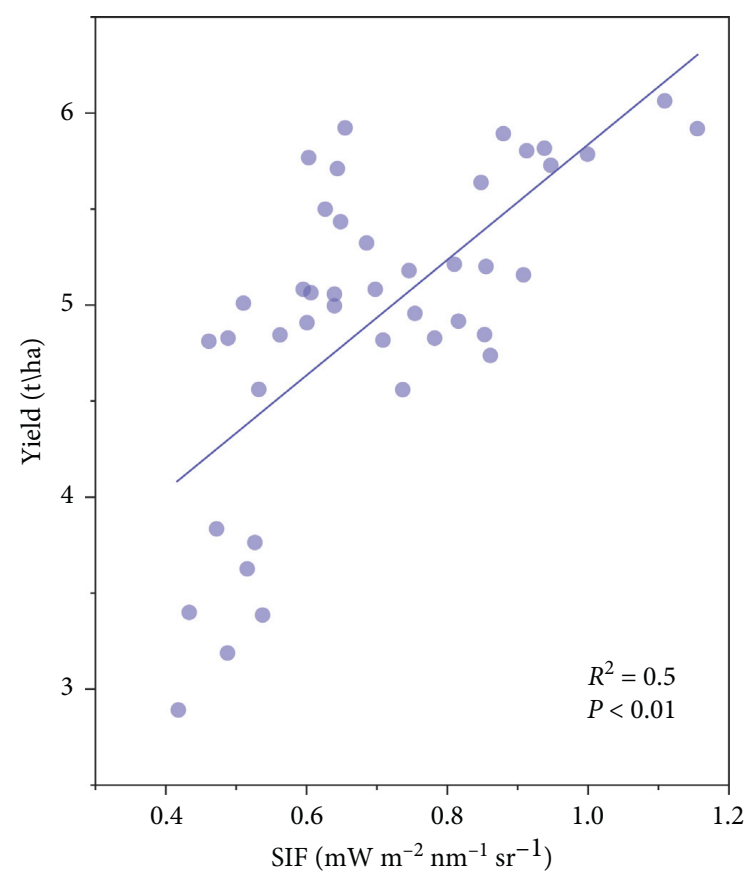

(a)

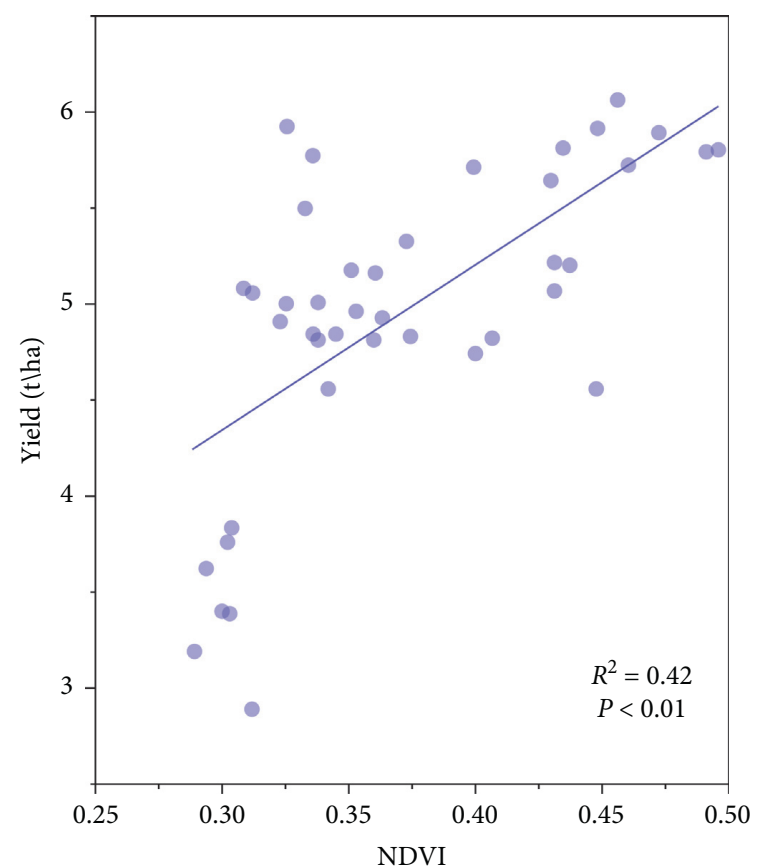

(b)

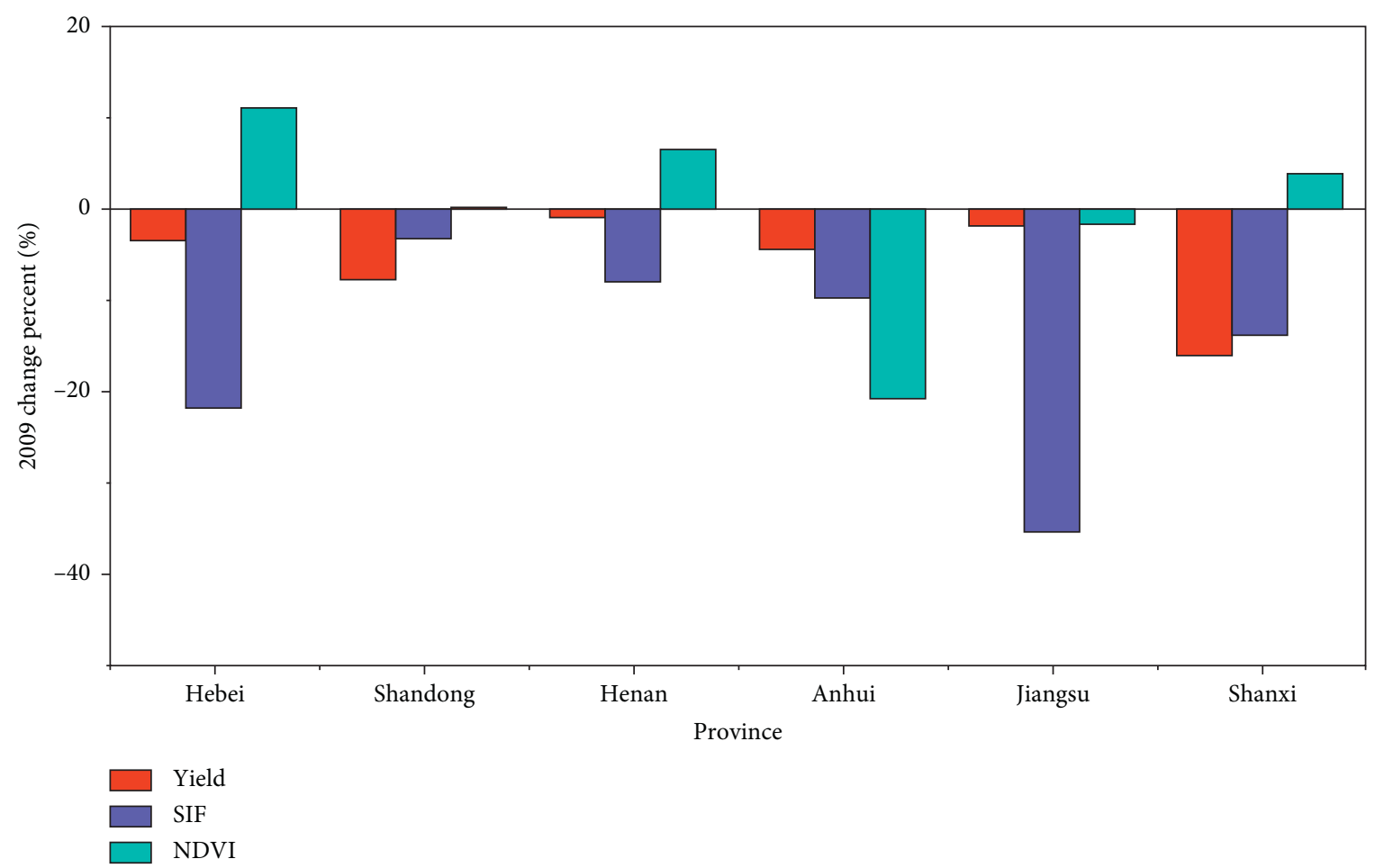

(c)

FIGURE 8: Comparison of wheat yield and wheat growing season mean (a) SIF and (b) NDVI over the whole study region at the province scale. (c) Percent of change in yield/SIF/NDVI compared with 2008-2014 multiyear values in the 2009 heat wave year.

Ground-based experiments using chlorophyll fluorescence to study heat stress in crops indicate why SIF can rapidly reflect the influence of heat stress. When photosynthetically active radiation is absorbed by leaves, some is used to drive photochemical reactions, some other is lost through nonphotochemical quenching, and another small part is remitted as fluorescence [62]. Thus, SIF not only includes the signal of "greenness" but also contains information about the biochemical, physiological, and metabolic functions of crops [29]. Traditional vegetation indices such as NDVI can only reflect the variations in crop "greenness" [26]. Wang et al. indicated that vegetation indices usually lag 


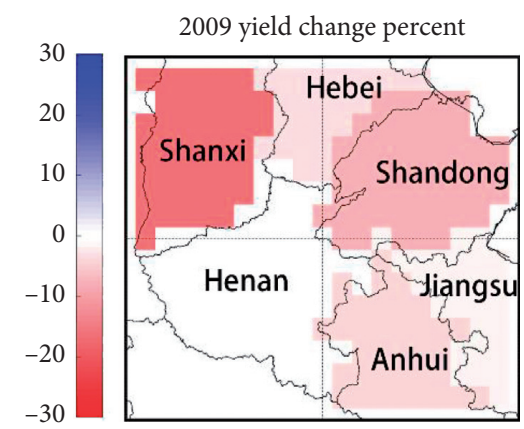

(a)

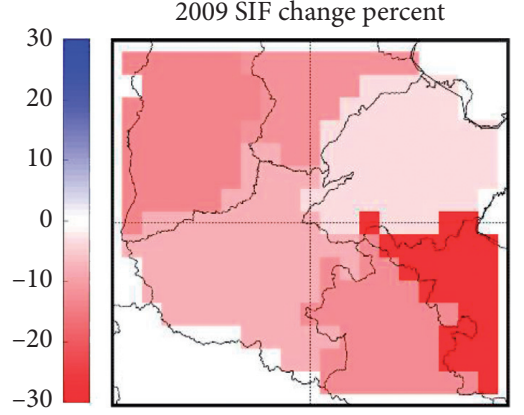

(b)

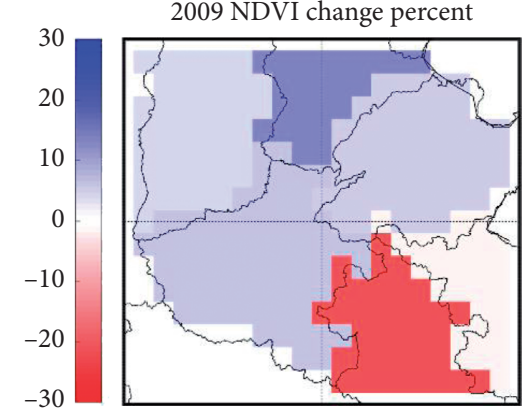

(c)

FIGURE 9: Spatial distributions of the 2009 change percentages (compared with multiyear values) during the time period 2008-2014 of (a) wheat yield, (b) wheat growing season mean SIF, and (c) wheat growing season mean NDVI. The location of each province is shown in (a), and panels (b) and (c) are the same as panel (a).

by half a month in response to changes in precipitation and temperature [63].

Considering the large emissions of carbon dioxide and the sharply increasing rate of emissions in China, even under moderate mitigation scenarios, severe heat waves are projected in the North China Plain [64]. Early detection of heat stress impacts on winter wheat crops in the NCP could limit economic losses through timely management decisions $[65,66]$.

4.3. Limitations of This Study. Due to the coarse spatial resolution of the current GOME-2 SIF product $\left(0.5^{\circ} \times 0.5^{\circ}\right)$, the GIMMS NDVI product was resampled from its original resolution $\left(1 / 12^{\circ} \times 1 / 12^{\circ}\right)$ to the same resolution as SIF. However, as compared with the original NDVI product, the NDVI with coarser spatial resolution shows less information (Figure S3 in Supplementary Materials). The annual variations in the wheat growing season average original NDVI were similar to the variations in the resampled NDVI (Figure S4 in Supplementary Materials). The difference between the resampled and original annual variations in all 6 provinces was small (3\%), especially in Henan Province, and the annual variations in the original NDVI and resampled NDVI were exactly the same (Figure S4(c) in Supplementary Materials).

However, as satellite products with much higher spatial and temporal resolution (such as the multispectral instrument onboard the Sentinel-2 with a $10 \mathrm{~m}$ spatial resolution and a 5-day temporal resolution from 2015 to the present day) are accumulating, in the future, these datasets will be available for long-term periods [67]. This is especially critical in data-poor, developing countries and can lead to more accurate field-level yield estimates in smallholder systems compared to coarser-resolution products [68]. Thus, the availability of long-term satellite products at higher spatial and temporal resolutions in the future may provide great potential for studying the effects of global climate change on cropping practices more accurately.

For the last 20 years, wheat planting areas have significantly changed. As indicated by Wang et al., the planting areas of wheat in the NCP increased by $950 \mathrm{~km}^{2}$ from 2001 to 2011 [55]. In this study, the spatial resolution of NDVI and
SIF products was $0.5^{\circ} \times 0.5^{\circ}\left(\sim 3025 \mathrm{~km}^{2}\right)$, which was approximately 3 times larger than the change in wheat planting areas. Thus, the change in wheat planting areas in the NCP may have a small influence on the results. Due to the limited temporal resolution of the SPAM and MODIS land cover products, the change in wheat planting areas was not considered. As more land cover products with finer temporal resolutions become available in the future, this issue could be addressed. In addition to the variations in wheat planting areas in the NCP, the changes in green-up date may also have impacts on the study of climate change in winter wheat. Thus, in future studies, the impacts of crop phenology variability will be included.

\section{Conclusions}

The results of this study indicated that temperature and the number of heat wave days have significantly increased in the NCP for the past 30 years. Spatially, the southern part of the study area suffered more heat wave days increasing trends per wheat growing season than those in the northern part. Along with higher temperature increasing trends and precipitation decreasing trends in the south of the NCP, there may be a serious risk of more extreme climate events, and wheat in the south of the NCP may be exposed to more serious heat waves. Thus, the early detection of heat wave impacts on wheat is essential. SIF shows an earlier and more sensitive response to heat waves in the NCP compared to NDVI. Furthermore, compared with NDVI, SIF can better capture the variations in wheat yield and the decline in yield due to heat waves. Earlier and more precise detections of the impacts of heat stress on wheat crops in the NCP could limit economic losses through timely management decisions.

\section{Data Availability}

Climate data were downloaded from https://crudata.uea.ac. $\mathrm{uk} / \mathrm{cru} / \mathrm{data} / \mathrm{hrg} /$, SIF data were downloaded from https:// gs614-avdc1-pz.gsfc.nasa.gov/pub/data/, NDVI data were downloaded from https://ecocast.arc.nasa.gov/data/pub/ gimms/, and yield data were downloaded from https:// data.stats.gov.cn/. 


\section{Conflicts of Interest}

The authors declare that there are no conflicts of interest regarding the publication of this paper.

\section{Acknowledgments}

The authors thank Dr. Lian Song of the Institute of Soil Science, Chinese Academy of Sciences, for providing suggestions for processing and analysing the data. This research was supported by the State Key Laboratory of Geohazard Prevention and Geoenvironment Protection Independent Research Project (Grant no. SKLGP2017Z005), the National Science Foundation for Young Scientists of China (Grant no. 32001191), and the National Natural Science Foundation of China (Grant no. 41801309).

\section{Supplementary Materials}

The following are available in Supplementary Materials: Figure S1: the linear trends of average annual precipitation (Pre). Figure S2: spatial maps of the trends in the annual mean (a) Pre in the winter wheat growth period from 1983 to 2014. The black dots in the figures indicate that the trends are statistically significant $(P<0.05)$. The middle panel shows trends of the spatial average of (b) Pre over latitude with $0.5^{\circ}$ bins. The right panel shows the histogram of the (c) Pre trends. Figure S3: spatial maps of the 1982-2014 average values of the wheat growing season mean NDVI at (a) the original spatial resolution $\left(1 / 12^{\circ} \times 1 / 12^{\circ}\right)$ and (b) the resampled spatial resolution $\left(0.5^{\circ} \times 0.5^{\circ}\right)$. Figure S4: linear trends of annual average NDVI with original and resampled spatial resolution of (a) Hebei, (b) Shandong, (c) Henan, (d) Anhui, (e) Jiangsu, and (f) Shanxi Provinces. (Supplementary Materials)

\section{References}

[1] IPCC, Climate Change 2014: Synthesis Report. Contribution of Working Groups I, II and III to the Fifth Assessment Report of the Intergovernmental Panel on Climate Change, IPCC, Geneva, Switzerland, 2014.

[2] Y. Li, Z. Xie, Y. Qin et al., "Drought under global warming and climate change: an empirical study of the loess plateau," Sustainability, vol. 11, no. 5, p. 1281, 2019.

[3] Y. Yin, Q. Tang, L. Wang et al., "Risk and contributing factors of ecosystem shifts over naturally vegetated land under climate change in China," Scientific Reports, vol. 6, p. 20905, 2016.

[4] D. Coumou and A. Robinson, "Historic and future increase in the global land area affected by monthly heat extremes," Environmental Research Letters, vol. 8, no. 3, Article ID 034018, 2013.

[5] H. C. J. Godfray, I. R. Crute, L. Haddad et al., "The future of the global food system," Philosophical Transactions of the Royal Society B: Biological Sciences, vol. 365, no. 1554, pp. 2769-2777, 2010.

[6] M. D. Jim, "Genetically modified (GM) crops: European and transatlantic divisions," Molecular Plant Pathology, vol. 15, no. 2, pp. 119-121, 2014.

[7] E. H. Elias, R. Flynn, O. J. Idowu et al., "Crop vulnerability to weather and climate risk: analysis of interacting systems and adaptation efficacy for sustainable crop production," Sustainability, vol. 11, no. 23, p. 6619, 2019.

[8] Z. Pinke and G. L. Lövei, "Increasing temperature cuts back crop yields in Hungary over the last 90 years," Global Change Biology, vol. 23, no. 12, pp. 5426-5435, 2017.

[9] O. Mazdiyasni and A. AghaKouchak, "Substantial increase in concurrent droughts and heatwaves in the United States," Proceedings of the National Academy of Sciences, vol. 112, no. 37, pp. 11484-11489, 2015.

[10] Z. Li, Z. Liu, W. Anderson et al., "Chinese rice production area adaptations to climate changes," Environmental Science and Technology, vol. 49, no. 4, pp. 2032-2037, 2015.

[11] P. V. V. Prasad and S. V. K. Jagadish, "Field crops and the fear of heat stress-opportunities, challenges and future directions," Procedia Environmental Sciences, vol. 29, pp. 36-37, 2015.

[12] T. Kindie, K. A. Pramod, M. Fasil et al., "Climate variability and change in Bihar, India: challenges and opportunities for sustainable crop production," Sustainability, vol. 9, no. 11, p. 1998, 2017.

[13] Q. Luo, G. O’Leary, J. Cleverly, and D. Eamus, "Effectiveness of time of sowing and cultivar choice for managing climate change: wheat crop phenology and water use efficiency," International Journal of Biometeorology, vol. 62, no. 6, pp. 1049-1061, 2018.

[14] Food and Agriculture Organization of the United Nations, The State of Food Security and Nutrition in the World 2019: Safeguarding against Economic Slowdowns and Downturns, UNICEF, New York, NY, USA, 2019.

[15] X. Zhai, D. Huang, S. Tang et al., "The emergy of metabolism in different ecosystems under the same environmental conditions in the agro-pastoral ecotone of northern China," Ecological Indicators, vol. 74, pp. 198-204, 2017.

[16] H. Zhao, X. Zhai, L. Guo et al., "Assessing the efficiency and sustainability of wheat production systems in different climate zones in China using emergy analysis," Journal of Cleaner Production, vol. 235, pp. 724-732, 2019.

[17] M. Djanaguiraman, D. Boyle, R. Welti et al., "Decreased photosynthetic rate under high temperature in wheat is due to lipid desaturation, oxidation, acylation, and damage of organelles," BioMed Central Plant Biology, vol. 18, no. 1, p. 55, 2018.

[18] T. Kobata, J. A. Palta, T. Tanaka et al., "Responses of grain filling in spring wheat and temperate-zone rice to temperature: similarities and differences," Field Crops Research, vol. 215, pp. 187-199, 2018.

[19] S. Pradhan, M. A. Babar, K. Robbins et al., "Understanding the genetic basis of spike fertility to improve grain number, harvest index, and grain yield in wheat under high temperature stress environments," Frontiers in Plant Science, vol. 10, p. 1481, 2019.

[20] C. J. Tucker, D. A. Slayback, J. E. Pinzon, S. O. Los, R. B. Myneni, and M. G. Taylor, "Higher northern latitude normalized difference vegetation index and growing season trends from 1982 to 1999," International Journal of Biometeorology, vol. 45, no. 4, pp. 184-190, 2001.

[21] H. Chu, S. Venevsky, C. Wu, and M. Wang, "NDVI-based vegetation dynamics and its response to climate changes at Amur-Heilongjiang River Basin from 1982 to 2015," Science of the Total Environment, vol. 650, pp. 2051-2062, 2019.

[22] J. Yao, Y. Chen, Y. Zhao et al., "Response of vegetation NDVI to climatic extremes in the arid region of Central Asia: a case study in Xinjiang, China," Theoretical and Applied Climatology, vol. 131, no. 3-4, pp. 1503-1515, 2018. 
[23] Z. Tan, H. Tao, J. Jiang, and Q. Zhang, "Influences of climate extremes on NDVI (normalized difference vegetation index) in the Poyang Lake Basin, China," Wetlands, vol. 35, no. 6, pp. 1033-1042, 2015.

[24] J. Wang, K. P. Price, and P. M. Rich, "Spatial patterns of NDVI in response to precipitation and temperature in the central Great Plains," International Journal of Remote Sensing, vol. 22, no. 18 , pp. 3827-3844, 2001.

[25] A. Karnieli, N. Agam, R. T. Pinker et al., "Use of NDVI and land surface temperature for drought assessment: merits and limitations," Journal of Climate, vol. 23, no. 3, pp. 618-633, 2010.

[26] L. Liu, X. Yang, H. Zhou et al., "Evaluating the utility of solarinduced chlorophyll fluorescence for drought monitoring by comparison with NDVI derived from wheat canopy," Science of the Total Environment, vol. 625, pp. 1208-1217, 2018.

[27] C. Frankenberg, A. Butz, and G. Toon, "Disentangling chlorophyll fluorescence from atmospheric scattering effects in O2 A-band spectra of reflected sun-light," Geophysical Research Letters, vol. 38, no. 3, 2011.

[28] P. Köhler, L. Guanter, and J. Joiner, "A linear method for the retrieval of sun-induced chlorophyll fluorescence from GOME-2 and SCIAMACHY data," Atmospheric Measurement Techniques, vol. 8, no. 6, pp. 2589-2608, 2015.

[29] A. Porcar-Castell, E. Tyystjärvi, J. Atherton et al., "Linking chlorophyll a fluorescence to photosynthesis for remote sensing applications: mechanisms and challenges," Journal of Experimental Botany, vol. 65, no. 15, pp. 4065-4095, 2014.

[30] Y. Zhang, X. Xiao, C. Jin et al., "Consistency between suninduced chlorophyll fluorescence and gross primary production of vegetation in North America," Remote Sensing of Environment, vol. 183, pp. 154-169, 2016.

[31] L. Guanter, C. Frankenberg, A. Dudhia et al., "Retrieval and global assessment of terrestrial chlorophyll fluorescence from GOSAT space measurements," Remote Sensing of Environment, vol. 121, pp. 236-251, 2012.

[32] C. Frankenberg, C. O’Dell, J. Berry et al., "Prospects for chlorophyll fluorescence remote sensing from the Orbiting Carbon Observatory-2," Remote Sensing of Environment, vol. 147, pp. 1-12, 2014.

[33] S. Du, L. Liu, X. Liu et al., "Retrieval of global terrestrial solarinduced chlorophyll fluorescence from TanSat satellite," Science Bulletin, vol. 63, no. 22, pp. 1502-1512, 2018.

[34] L. Guanter, I. Aben, P. Tol et al., "Potential of the tropospheric monitoring instrument (TROPOMI) onboard the sentinel-5 precursor for the monitoring of terrestrial chlorophyll fluorescence," Atmospheric Measurement Techniques, vol. 8, no. 3, pp. 1337-1352, 2015.

[35] C. Van der Tol, W. Verhoef, and A. Rosema, "A model for chlorophyll fluorescence and photosynthesis at leaf scale," Agricultural and Forest Meteorology, vol. 149, no. 1, pp. 96105, 2009.

[36] L. Guanter, Y. Zhang, M. Jung et al., "Global and time-resolved monitoring of crop photosynthesis with chlorophyll fluorescence," Proceedings of the National Academy of Sciences, vol. 111, no. 14, pp. E1327-E1333, 2014.

[37] X. Mo, S. Liu, Z. Lin et al., "Patterns of evapotranspiration and GPP and their responses to climate variations over the North China Plain," Acta Geographica Sinica, vol. 66, no. 5, pp. 589-598, 2011.

[38] Z. Zhang and C. Lu, "Spatio-temporal pattern change of winter wheat production and its implications in the north China plain," Sustainability, vol. 11, 2019.
[39] A. Duo, W. Zhao, X. Qu et al., "Spatio-temporal variation of vegetation coverage and its response to climate change in North China plain in the last 33 years," International Journal of Applied Earth Observation and Geoinformation, vol. 53, pp. 103-117, 2016.

[40] D. Xiao, F. Tao, Y. Liu et al., "Observed changes in winter wheat phenology in the North China Plain for 1981-2009," International Journal of Biometeorology, vol. 57, no. 2, pp. 275-285, 2013.

[41] D. F. Calderini, R. Savin, G. A. Slafer et al., "Final grain weight in wheat as affected by short periods of high temperature during pre- and post-anthesis under field conditions," Functional Plant Biology, vol. 26, no. 5, pp. 453-458, 1999.

[42] V. Kaur and R. Behl, "Grain yield in wheat as affected by short periods of high temperature, drought and their interaction during pre- and post-anthesis stages," Cereal Research Communications, vol. 38, no. 4, pp. 514-520, 2010.

[43] E. Raei, M. R. Nikoo, A. AghaKouchak et al., "GHWR, a multi-method global heatwave and warm-spell record and toolbox," Scientific Data, vol. 5, p. 180206, 2018.

[44] L. You, S. Wood, U. Wood-Sichra, and W. Wu, "Generating global crop distribution maps: from census to grid," Agricultural Systems, vol. 127, pp. 53-60, 2014.

[45] L. You and S. Wood, "An entropy approach to spatial disaggregation of agricultural production," Agricultural Systems, vol. 90, no. 1-3, pp. 329-347, 2006.

[46] J. Tan, Z. Li, P. Yang et al., "Spatial evaluation of crop maps by the spatial production allocation model in China," Journal of Applied Remote Sensing, vol. 8, no. 1, p. 085197, 2014.

[47] M. Friedl, A. Strahler, J. Hodges et al., ISLSCP II MODIS (Collection 4) IGBP Land Cover, 2000-2001, ORNL DAAC, Oak Ridge, TN, USA, 2017.

[48] R. Fernandes and S. G. Leblanc, "Parametric (modified least squares) and non-parametric (Theil-Sen) linear regressions for predicting biophysical parameters in the presence of measurement errors," Remote Sensing of Environment, vol. 95, no. 3, pp. 303-316, 2005.

[49] S. Rahmstorf, G. Foster, and N. Cahill, "Global temperature evolution: recent trends and some pitfalls," Environmental Research Letters, vol. 12, no. 5, Article ID 054001, 2017.

[50] W. Xue, J. Guo, Y. Zhang et al., "Declining diurnal temperature range in the North China Plain related to environmental changes," Climate Dynamics, vol. 52, no. 9-10, pp. 6109-6119, 2019.

[51] H. Jin, S. Li, G. Cheng, W. Shaoling, and X. Li, "Permafrost and climatic change in China," Global and Planetary Change, vol. 26, no. 4, pp. 387-404, 2000.

[52] S. Peng, J. Huang, J. E. Sheehy et al., "Rice yields decline with higher night temperature from global warming," Proceedings of the National Academy of Sciences, vol. 101, no. 27, pp. 9971-9975, 2004.

[53] N. A. Streck, "Climate change and agroecosystems: the effect of elevated atmospheric $\mathrm{CO}_{2}$ and temperature on crop growth, development, and yield," Ciência Rural, vol. 35, no. 3 , pp. 730-740, 2005.

[54] N. Nicholls, C. Skinner, M. Loughnan, and N. Tapper, "A simple heat alert system for Melbourne, Australia," International Journal of Biometeorology, vol. 52, no. 5, pp. 375-384, 2008.

[55] X. Wang, X. Li, M. Tan et al., "Remote sensing monitoring of changes in winter wheat area in North China Plain from 2001 to 2011," Transactions of the Chinese Society of Agricultural Engineering, vol. 31, no. 8, pp. 190-199, 2015. 
[56] P. Zhai and X. Pan, "Change in extreme temperature and precipitation over northern China during the second half of the 20th century," Acta Geographica Sinica, vol. 58, no. S1, pp. 1-10, 2003.

[57] A. S. Dias, J. Semedo, J. C. Ramalho, and F. C. Lidon, "Bread and durum wheat under heat stress: a comparative study on the photosynthetic performance," Journal of Agronomy and Crop Science, vol. 197, no. 1, pp. 50-56, 2011.

[58] G. Fontana, A. Toreti, A. Ceglar et al., "Early heat waves over Italy and their impacts on durum wheat yields," Natural Hazards and Earth System Sciences Discussions, vol. 3, no. 5, 2015.

[59] Q. Jiang, Y. Yue, and L. Gao, "The spatial-temporal patterns of heatwave hazard impacts on wheat in northern China under extreme climate scenarios," Geomatics, Natural Hazards and Risk, vol. 10, no. 1, pp. 2346-2367, 2019.

[60] A. Wreford and W. N. Adger, "Adaptation in agriculture: historic effects of heat waves and droughts on UK agriculture," International Journal of Agricultural Sustainability, vol. 8 , no. 4 , pp. 278-289, 2010.

[61] L. Song, L. Guanter, K. Guan et al., "Satellite sun-induced chlorophyll fluorescence detects early response of winter wheat to heat stress in the Indian Indo-Gangetic Plains," Global Change Biology, vol. 24, no. 9, pp. 4023-4037, 2018.

[62] N. R. Baker, "Chlorophyll fluorescence: a probe of photosynthesis in vivo," Annual Review of Plant Biology, vol. 59, no. 1, pp. 89-113, 2008.

[63] J. Wang, P. M. Rich, K. P. Price, and W. D. Kettle, "Relations between NDVI and tree productivity in the central Great Plains," International Journal of Remote Sensing, vol. 25, no. 16, pp. 3127-3138, 2004.

[64] S. Kang and E. A. B. Eltahir, "North China Plain threatened by deadly heatwaves due to climate change and irrigation," Nature Communications, vol. 9, no. 1, p. 2894, 2018.

[65] J. R. Hunt, P. T. Hayman, R. A. Richards, and J. B. Passioura, "Opportunities to reduce heat damage in rain-fed wheat crops based on plant breeding and agronomic management," Field Crops Research, vol. 224, pp. 126-138, 2018.

[66] N. Akter and M. R. Islam, "Heat stress effects and management in wheat," A Review, Agronomy for Sustainable Development, vol. 37, no. 5, p. 37, 2017.

[67] C. Kubitza, V. V. Krishna, U. Schulthess et al., "Estimating adoption and impacts of agricultural management practices in developing countries using satellite data. A scoping review," Agronomy for Sustainable Development, vol. 40, no. 3, pp. 121, 2020.

[68] J. Meha, S. Amit, Balwinder-Singh et al., "Mapping smallholder wheat yields and sowing dates using micro-satellite data," Remote Sensing, vol. 8, no. 10, 860 pages, 2016. 